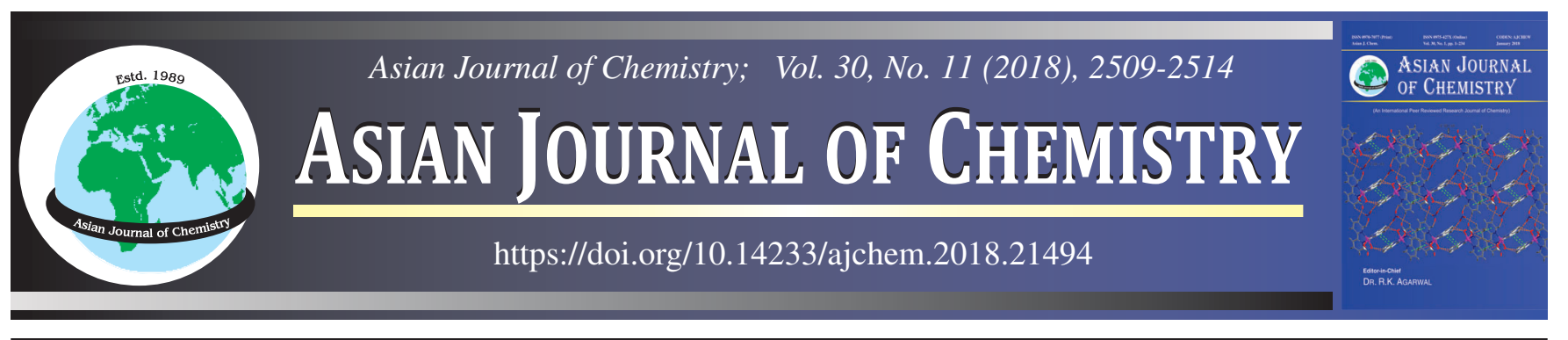

\title{
Synthesis, Characterization and Flux Evaluation of Chitosan tri-polyphosphate Membrane and Chitosan/tri-polyphosphate Membrane Impregnated with Zinc Oxide Nanoparticles
}

\section{A. Febriasari ${ }^{1, *}$, D. Siswanta ${ }^{2}$, N. Riyanto ${ }^{1}$, N. Hidayat Aprilita ${ }^{2}$ and F. Silvianti ${ }^{3}$}

${ }^{1}$ Department of Chemical Engineering, Universitas Serang Raya, Jl.Raya Cilegon-Serang Km. 05, Drangong, Taktakan, Kota Serang, Banten 42162, Indonesia

${ }^{2}$ Department of Chemistry, Universitas Gadjah Mada, Jl. Sekip Utara BLS 21, Bulaksumur, Sinduadi, MLati, Kabupaten Sleman, Daerah Istimewa Yogyakarta 55281, Indonesia

${ }^{3}$ Politeknik ATK Yogyakarta, Jl. Ringroad Selatan, Glugo, Panggungharjo, Sewon, Bantul, Yogyakarta 55188, Indonesia

*Corresponding author: E-mail: arifinafebriasari@lppmunsera.org; arifinafebriasari25@gmail.com

Received: 4 June 2018;

Accepted: 19 July 2018;

Published online: 27 September 2018;

AJC-19103

| The present study report the synthesis of chitosan tri-polyphosphate (CTP) membrane and of CTP membrane impregnated with zinc oxide nanoparticles. The zinc oxide nanoparticles was intended to improve the antifouling performance in membrane. Synthesis was performed by mixing method. In the CTP membrane synthesis, tri-polyphosphate concentrations were varied. Meanwhile, in impregnation of the CTP membrane with zinc oxide, the ratios of chitosan to zinc oxide nanoparticles were varied. SEM-EDS analysis showed the biggest zinc oxide nanoparticle distribution occurred with a chitosan to zinc oxide ratio of 2:1 (32.08\%). The addition of zinc oxide nanoparticles occurred the wider pore radius of membranes. Water contact angle analysis showed that chitosan, CTP and CTP-zinc oxide membranes are hydrophilic and the additions of zinc oxide affect the decrease in hydrophilic property of membranes. Membrane performance test on methylene blue showed reduced flux at the most stable time in CTP-zinc oxide $(2: 1)$ membrane and maximum flux recovery ratio was present in CTP-zinc oxide (2:1).

Keywords: Membrane, Chitosan, Tri-polyphosphate, Zinc oxide nanoparticles, Antifouling performance.

ᄂ - - - - - - - - - - - - - - - - - - - - - - - - - - - -

\section{INTRODUCTION}

A membrane is a thin lining material which can selectively transport the mass of a component as a result of thrust force and the chemical and physical properties between the membrane and permeated compound [1]. Membranes are often used for purification, in processes such as haemodialysis [2], biodiesel purification [3] and waste water purification [4]. Compared with other waste-water treatment methods such as adsorption and coagulation, a membrane is effective because it saves time, is continuous and conserves energy [5]. However, this method has some drawbacks, one of which is fouling [6,7]. Some studies have been conducted into ways to prevent fouling in membrane-based filtration processes, including research into bioreactor membranes in which microorganisms act to degrade contaminants, thus minimizing fouling in the filtration process and improving the efficiency of the membranes used [8]. Some studies have also used photocatalysis to solve the fouling issue [9].

Recently, research into membrane synthesis from natural polymers has been carried out, looking at, for example, membranes made from cellulose [10], poly-eugenol [11] and chitosan $[12,13]$. Chitosan is one of the natural polymers which is often used to create membranes, because it is proven to be a good adsorbent of metal compounds [14] and dyes [15,16]. Chitosan is a natural polymer created through the deacetylation of chitin, usually sourced from shrimp or crab skin [17]. Liu et al. [18] used chitosan membrane cross-linked with tri-polyphosphates to remove humic acid from water, resulting in polyelectrolyte complex (PEC) CTP membrane which can serve as a good adsorbent.

There has been recent rapid development of inorganic nanoparticles for environmental applications [19]. Inorganic nanoparticles have the potential for degrading pollutants by

This is an open access journal, and articles are distributed under the terms of the Creative Commons Attribution-NonCommercial 4.0 International (CC BY-NC 4.0) License, which allows others to copy and redistribute the material in any medium or format, remix, transform, and build upon the material, as long as appropriate credit is given and the new creations are licensed under the identical terms. 
oxidizing or reducing them [20]. Nano-sized inorganic oxides can be more reactive than at normal size [21]. The present study modified complex polyelectrolyte membranes with nanoparticles to reduce fouling effects in the membrane. The impregnation of nanoparticles into a membrane is expected to degrade pollutants trapped on the membrane surface, thus preventing fouling [22-25].

The pollutant used to test membrane performance in this study was methylene blue dye. It has high solubility in water and so in the attachment process a large amount of dye is lost with waste water [26].

This paper presents the results of the characterization of the performance testing on methylene blue solution of complex polyelectrolyte membrane made of CTP combined with zinc oxide nanoparticles. One of the weaknesses of chitosan membrane is its instability in acidic $\mathrm{pH}$. To improve the stability of chitosan membrane, one possible method is cross-linking it with another substance. In this study, chitosan was crosslinked with tri-polyphosphate as a complex polyelectrolyte membrane [27]. Zinc oxide nanoparticles, which have the potential to degrade pollutants, were impregnated into the membrane to improve its antifouling properties [28].

\section{EXPERIMENTAL}

The materials used in this study were industrial-grade chitosan (with $85.87 \%$ deacetylation degree) purchased from CV. ChiMultiguna. Sodium tripolyphosphate, acetic acid, zinc oxide nanoparticles $<50 \mathrm{~nm}$ size (BET) were purchased from Sigma Aldrich and Merck.

The instruments used in this study were a Teflon membrane mould with a $10 \mathrm{~cm}$ diameter, a set of membrane performance test equipment, SEM-EDX (JSM-6360L) test equipment, FTIR (Shimadzu FT-IR 8201PC) test equipment and pore size analysis by BET $\left(\mathrm{N}_{2}\right.$ adsorption at $\left.77.35 \mathrm{~K}\right)$ equipment.

Synthesis of chitosan membrane: Chitosan was dissolved in $2 \%$ acetic acid at a ratio of 1:50. This chitosan solution was then stirred for $3 \mathrm{~h}$ while heating at $60{ }^{\circ} \mathrm{C}$. After the chitosan was fully dissolved, $50 \mathrm{~mL}$ of the solution was moulded in a Teflon mould and oven-dried at $60^{\circ} \mathrm{C}$. Once dry, the membrane was removed from the mould and characterized.

Synthesis of chitosan tri-polyphosphate membrane: Chitosan was dissolved in 2\% acetic acid at a ratio of 1:50 and then heated for $3 \mathrm{~h}$ at $60{ }^{\circ} \mathrm{C}$. Once it was homogenous, sodium tri-polyphosphate was added at $0.5 \%, 1 \%$ and $1.5 \%$ concentration variations (each at $\mathrm{pH} 4$ ) until a clear suspension was formed. Then $50 \mathrm{~mL}$ of solution was moulded using a Teflon mould and oven-dried at $60^{\circ} \mathrm{C}$. The formed membrane was then removed from the mould and characterized.

Synthesis of chitosan-sodium tri-polyphosphate (TPP)zinc oxide nanoparticle (CTP-zinc oxide) membrane: Chitosan was dissolved in $2 \%$ acetic acid with a ratio of 1:50, then stirred and heated at $60^{\circ} \mathrm{C}$. After the chitosan solution was homogenous, it was mixed with zinc oxide nanoparticles. The ratios of chitosan by weight to zinc oxide nanoparticles by weight were $2: 1,4: 1$ and $8: 1$ respectively. The solution was stirred at 1,300 rpm for $30 \mathrm{~min}$. Once it was homogenous, TPP solution ( $\mathrm{pH} 4$ ) was added until a clear suspension was formed. $50 \mathrm{~mL}$ of the resulting solutions were taken to be moulded in Teflon moulds and oven-dried at $60^{\circ} \mathrm{C}$.

Application and performance test: Application and performance testing was performed to determine the effect of application time on flux value. Flux recovery ratio (FRR) was also calculated to determine the antifouling properties of the membranes. Flux recovery ratio value was calculated by the formula [29]:

$$
\text { Flux recovery ratio }(\%)=\frac{\mathrm{J}_{\mathrm{w} 2}}{\mathrm{~J}_{\mathrm{w} 1}} \times 100
$$

where $J_{\mathrm{w} 1}$ is the flux value of the membrane when passed by the target compound and $\mathbf{J}_{\mathrm{w} 2}$ is flux value after backwashing of the membrane by demineralized water.

Membrane characterization: Characterization of the CTP and CTP-zinc oxide membranes was performed. The characterization methods used were scanning electron microscope with energy dispersive X-ray spectroscopy (SEM-EDX), surface analysis by BET and water contact angle measurement. Characterization of zinc oxide nanoparticles was performed by particle size analyser.

Analysis of target compound: The target compound used as artificial 'waste' in this study was methylene blue pigment. Analysis of methylene blue was performed by spectrophotometer UV-visible of wavelength [30].

\section{RESULTS AND DISCUSSION}

Preparation and characterization of chitosan-TPP (CTP) membrane: Preparation of chitosan-TPP membrane was performed by the mixing and evaporation method. The dominant polymer solution, which was chitosan in acetic acid, was added with sodium tri-polyphosphate (TPP) with $0.5,1.0$ and $1.5 \%$ concentration variations at $\mathrm{pH} 5$.

The characterization results by FTIR described that the peak of chitosan at $3448.58 \mathrm{~cm}^{-1}$ wavenumber showed hydroxide bond vibration. The peaks at $1635.64 \mathrm{~cm}^{-1}$ and 1558.48 $\mathrm{cm}^{-1}$ wavenumbers showed $\mathrm{P}=\mathrm{O}$ stretching in the $\mathrm{P}-\mathrm{OH}$ bond and $-\mathrm{NH}_{3}{ }^{+}$. The more percentage of TPP, the sharper the peak at $1635.64 \mathrm{~cm}^{-1}$ wavenumber. Meanwhile, the peak at 1265.30 $\mathrm{cm}^{-1}$ wavenumber showed a $\mathrm{P}=\mathrm{O}$ bond in phosphate (Fig. 1). In acidic $\mathrm{pH}$, chitosan was in cations form, so it had an $\mathrm{NH}_{3}{ }^{+}$ group which could bind with anion TPP [31]. Fig. 2 is an illustration of the bond between chitosan and TPP [32].

The results of SEM characterization in the chitosan membranes cross-linked with TPP are shown in Fig. 3. It can be seen from Fig. 3 that the $1.5 \%$ CTP membrane shows pore strain. However, the surfaces of the $0.5 \%$ CTP and the $1 \%$ CTP appear tight and there was no difference between and the chitosan membrane without TPP.

Preparation of CTP-zinc oxide membrane: The chitosan membrane which was cross-linked with TPP was impregnated with zinc oxide nanoparticles. The mixing of chitosan-TPP with zinc oxide was performed at 1,300 rpm until homogenous. It was dried at $60^{\circ} \mathrm{C}$ until a CTP-zinc oxide membrane film was formed. Characterization was performed by SEM-EDS analyses. The results of SEM-EDS characterization of CTPzinc oxide membranes are shown in Figs. 4 and 5. 


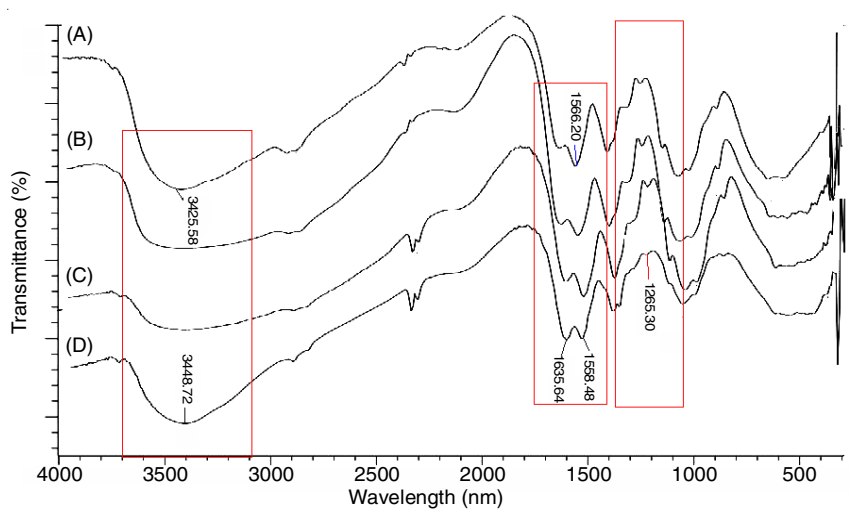

Fig. 1. Infrared spectrum of chitosan (A), $0.5 \%$ chitosan-TPP (B), $1 \%$ chitosan-TPP (C), $1.5 \%$ chitosan-TPP (D) membranes
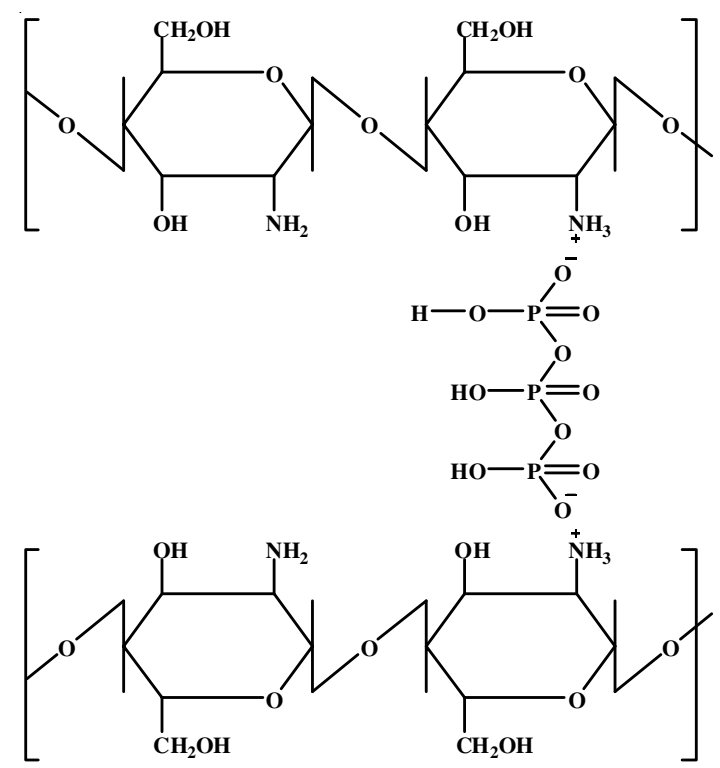

Fig. 2. Structure of cross-linking between chitosan and TPP

The result of SEM characterization shows that the more the mass of zinc oxide nanoparticles impregnated into the membrane, the rougher the membrane surface. The SEM pictures of cross section membrane describe that some of nanoparticles are trapped insert of the membrane and more of them are accumulated in membrane surface. Meanwhile, the EDS spectra show the percentage of zinc oxide nanoparticles distribution in membranes with $1: 8$ ratio was $5.39 \% ; 1: 4$ ratio was $6.45 \%$ and $1: 2$ ratio was $32.08 \%$. The percentage of zinc oxide nanoparticle distribution affected the morphological structure of the membranes and the involvement of zinc oxide nanoparticles in the compound adsorption process in the membrane. From the SEM-EDS characterization, the molecule structure of the CTP-zinc oxide nanoparticles is predicted in Fig. 6 .

BET analysis: This analysis determines total pore volume, surface area and average pore size of the membranes, based on membrane adsorption of nitrogen at $77.35 \mathrm{~K}$. Table-1 presents membrane comparison based on these measurements.

\begin{tabular}{|c|c|c|c|c|}
\hline \multicolumn{5}{|c|}{$\begin{array}{c}\text { TABLE-1 } \\
\text { PHYSICO-CHEMICAL DATA OF CHITOSAN/TRI- } \\
\text { POLYPHOSPHATE AND CHITOSAN/TRI-POLYPHOSPHATE } \\
\text { MEMBRANE IMPREGNATED WITH ZINC } \\
\text { OXIDE NANOPARTICLES }\end{array}$} \\
\hline Membrane & $\begin{array}{l}\text { Total pore } \\
\text { volume } \\
\left(10^{-2} \mathrm{cc} / \mathrm{g}\right)\end{array}$ & $\begin{array}{l}\text { Average } \\
\text { pore } \\
\text { radius } \\
\left(10^{1} \AA\right)\end{array}$ & $\begin{array}{c}\text { BET } \\
\text { surface } \\
\text { area } \\
\left(\mathrm{m}^{2} / \mathrm{g}\right) \\
\end{array}$ & $\begin{array}{c}\text { Water } \\
\text { contact } \\
\text { angle }\left(^{\circ}\right)\end{array}$ \\
\hline Chitosan & 2.341 & 4.128 & 11.340 & 46 \\
\hline СТР $0,5 \%$ & 2.717 & 3.568 & 15.225 & 48 \\
\hline CTP $1 \%$ & 2.163 & 4.259 & 10.159 & 50 \\
\hline CTP $1,5 \%$ & 2.221 & 4.436 & 10.014 & 54 \\
\hline CTP-zinc oxide (8:1) & 1.956 & 4.671 & 8.375 & 64 \\
\hline CTP-zinc oxide (4:1) & 2.037 & 5.039 & 8.085 & 66 \\
\hline CTP-zinc oxide (2:1) & 2.347 & 4.683 & 10.021 & 66 \\
\hline
\end{tabular}

Table-1 described the comparison of total pore volume, average pore radius and BET surface area of the membranes. The zinc oxide addition influence the pore radius of CTP membranes. The maximum pore radius of the membrane was in CTP-zinc oxide (4:1) membranes. However, BET analysis showed that it does not influential on total pore volume and surface area.
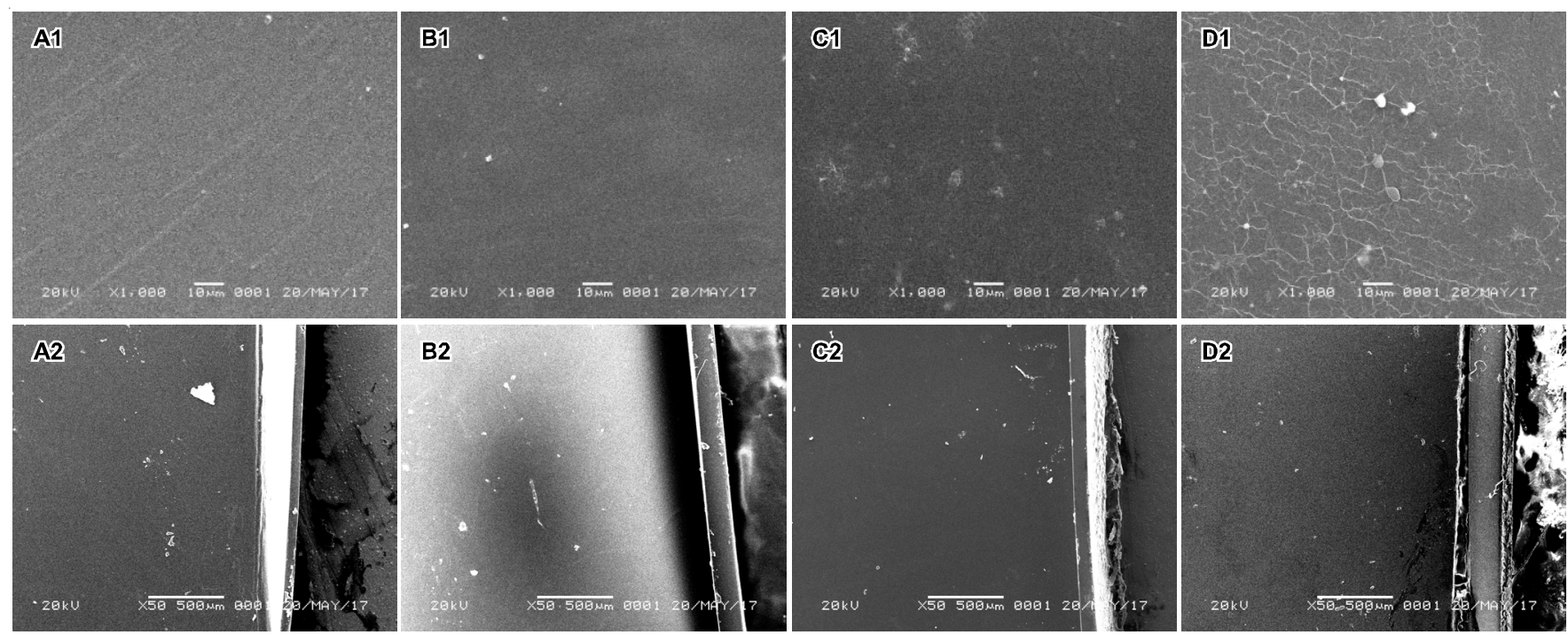

Fig 3. SEM characterization: top view (A1) and cross section view (A2) of chitosan membrane; top view (B1) and cross section view (B2) of $0.5 \%$ chitosan-TPP membrane; top view (C1) and cross section view (C2) of $1 \%$ chitosan-TPP membrane; top view (D1) and cross section view (D2) of $1.5 \%$ chitosan-TPP membrane 

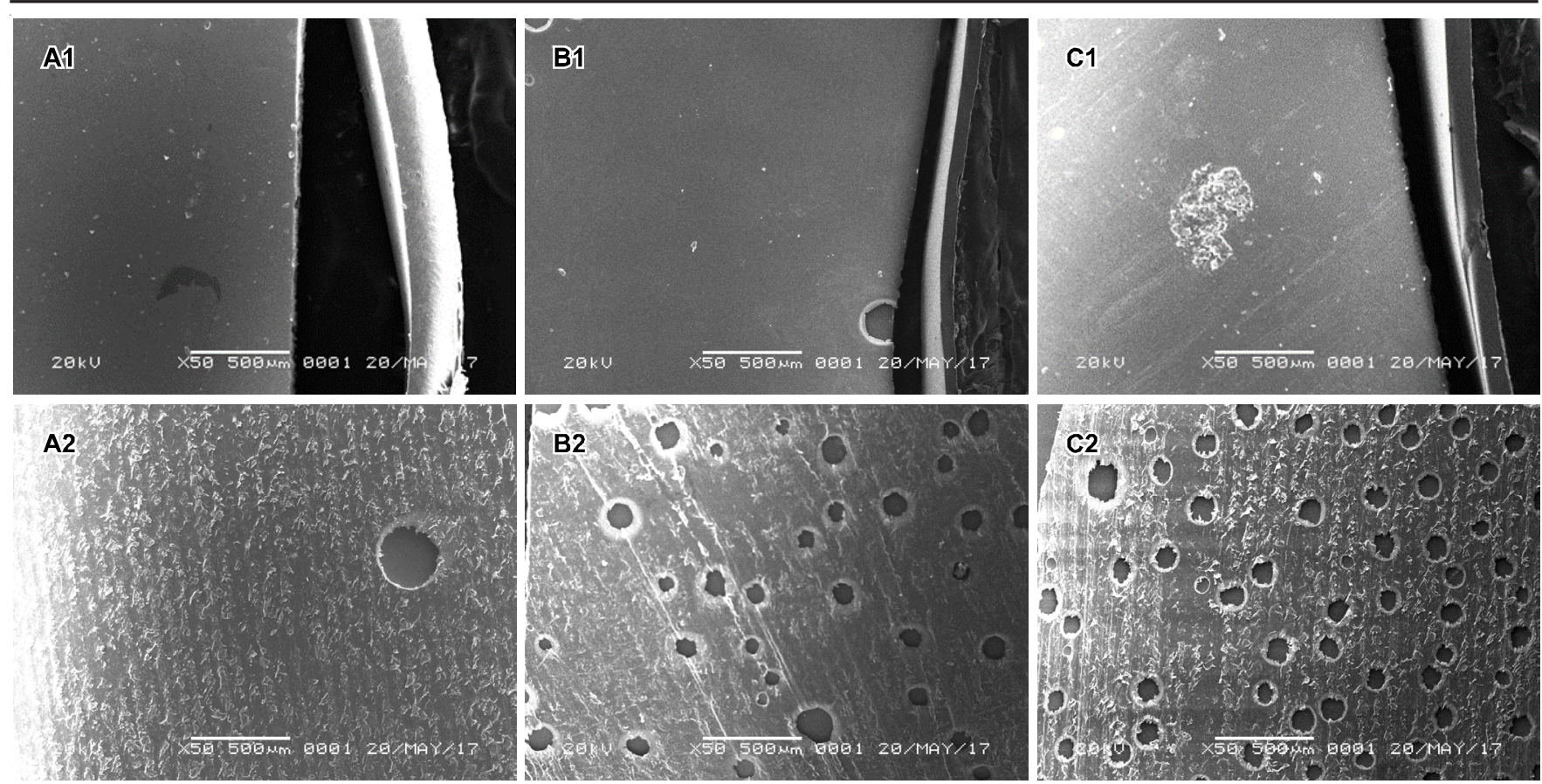

Fig. 4. SEM characterization results of CTP-zinc oxide 1:8 cross section membrane at 50x magnification (A1) and membrane surface 50x magnification (A2); CTP-zinc oxide 1:4 cross section membrane with 50x magnification (B1) and membrane surface 50x magnification (B2); CTP-zinc oxide 1:2 cross section membrane with 50x magnification (C1) and membrane surface 50x magnification (C2)
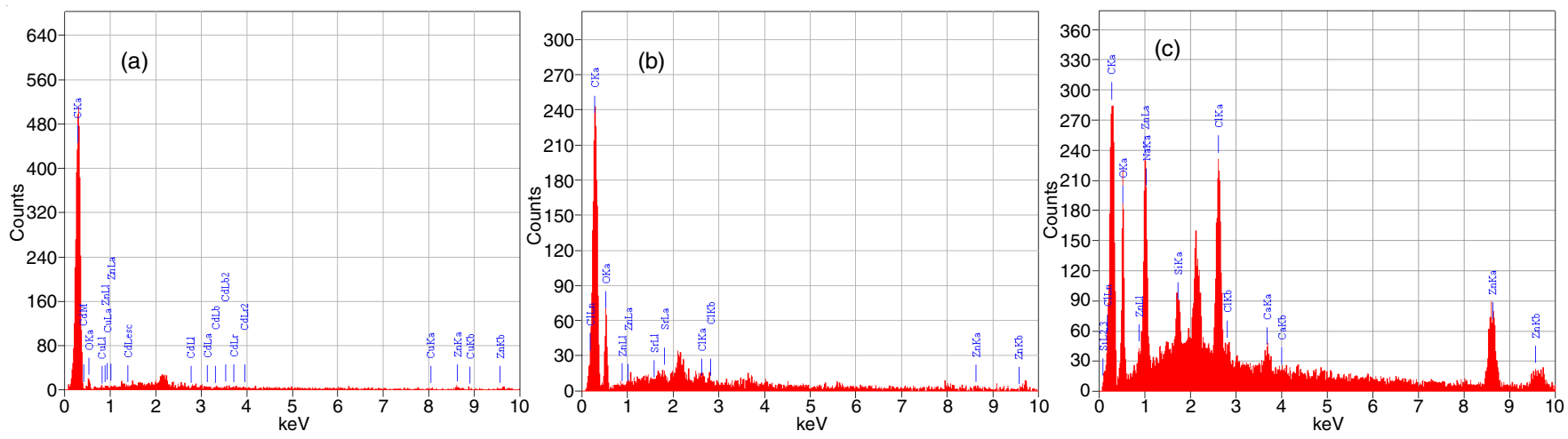

Fig. 5. EDS spectra of CTP-zinc oxide 1:8 (a), 1:4 (b) and 1:2 (c) membranes
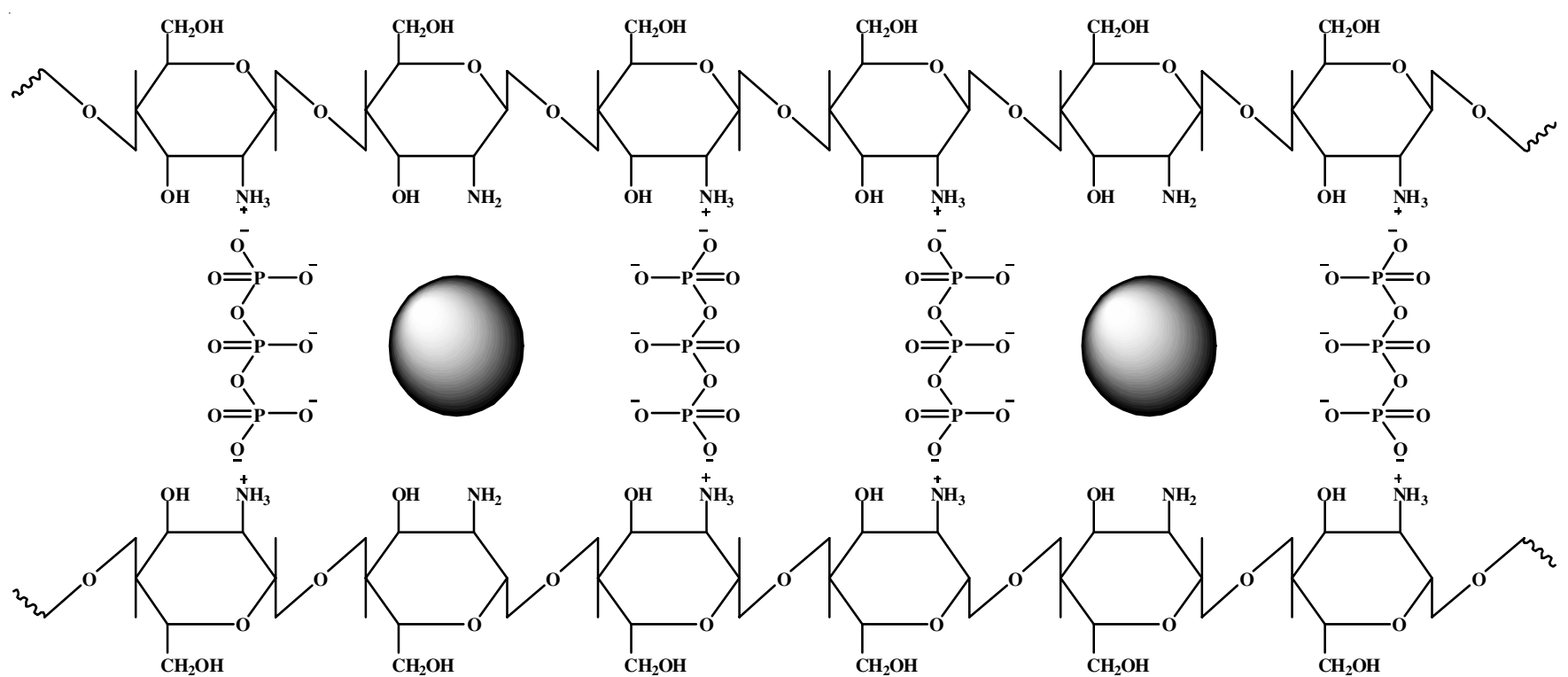

Fig. 6. Prediction of CTP-zinc oxide molecule structure 
Water contact angle: The measurement of water contact angle was performed by measuring the angle of water contact with the membranes. This measurement aims to evaluate the hydrophilicity of the membrane surface [33]. Table-1 and Fig. 7 present the results of the water contact angle measurements. The angle between a drop of water and the membrane surface were measured and the angle values shown in Table-1.

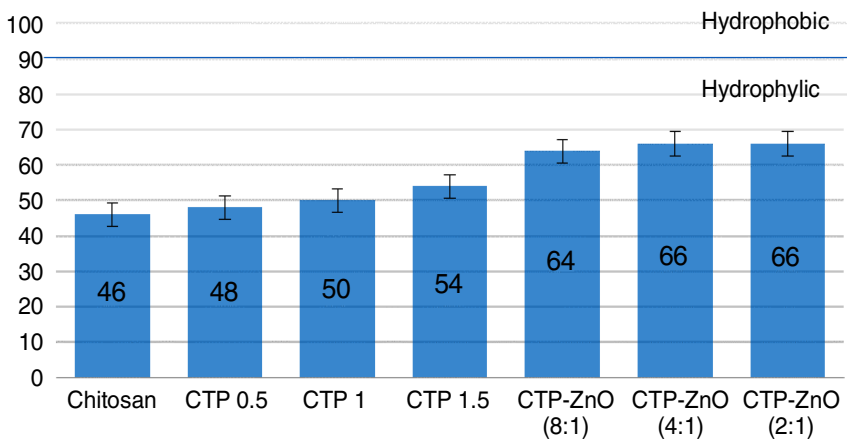

Fig. 7. Water contact angles of the membranes

The chart above shows that the membranes have hydrophilic properties and they are decreasing while the additions of tri-polyphosphate and zinc oxide nanoparticles. The intermolecular bonding between membrane and water was conducted by van der Waals force. The presence of tri-polyphosphate and zinc oxide nanoparticles may inhibit the adsorption of water since they could obstruct the hydroxyl and amine functional group of membrane.

Application and permeation test of CTP and CTP-zinc oxide membranes: Membrane application was demonstrated using the methylene blue dye. Methylene blue solution with a $4 \mathrm{ppm}$ concentration was passed through the membranes using membrane performance test equipment. A schematic diagram of the equipment is shown in Fig. 8.

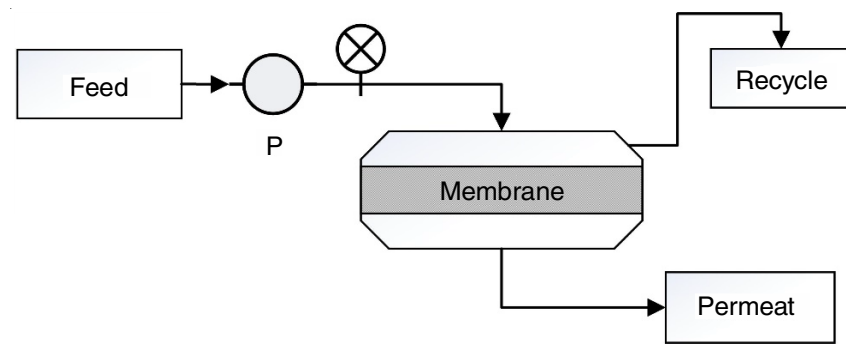

Fig. 8. Schematic diagram of membrane performance test equipment

Transport membranes take place in reverse osmosis (RO). Feed solution were pumped through the membrane and the pressure was controlled by valve in 10 bar. The filtration was varied by measurement time. The water of methylene blue solution were diffused through the membrane since the CTP membranes are hydrophilic and methylene blue molecules were trapped in the membrane surface. Permeate flux was measured in 1, 2, 3, 4 and $5 \mathrm{~h}$. The time variable was chosen in order to evaluate the stability of flux permeate of the membrane transport. Performance test produced graphs of percentage of permeated flux with time and antifouling performance shown by flux recovery ratio (FRR) value [34]. The graph of the effect of time on flux is shown in Fig. 9.

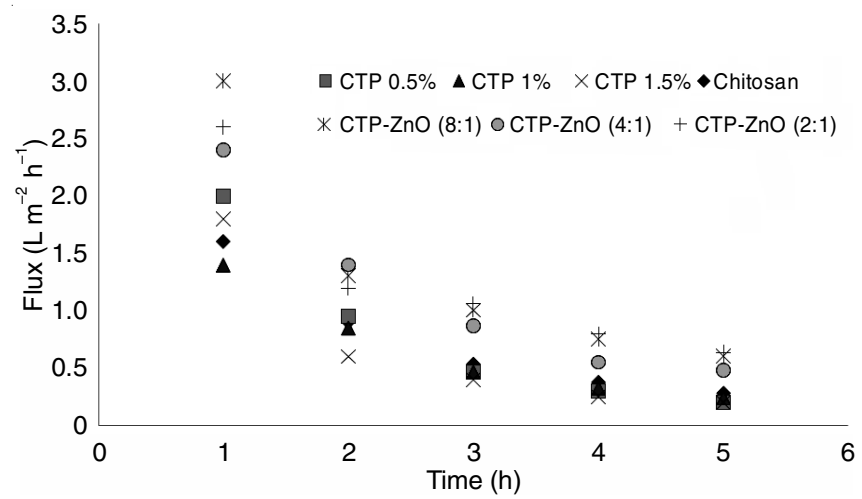

Fig. 9. Graph of the relationship between permeated flux and time

Fig. 9 showed reduced flux with time. There was significant flux reduction in the $0.5 \%$ CTP membrane. Meanwhile, the most stable flux was found in CTP-zinc oxide (2:1) membrane. The flux decrease since the first minute of transport, this indicate that the fouling of methylene blue has appeared in the surface of membrane. Determination of antifouling performance in the membranes was performed by calculating FRR value, by comparing the value of permeated flux of the membranes after backwashing using distilled water and comparing this with the flux value before backwashing.

Fig. 10 describes that the addition of zinc oxide nanoparticles showed increased FRR values. Flux recovery ratio values (Table-2) show the antifouling performance of membrane. The higher FRR value, the higher the antifouling potential of the membrane. Zinc oxide nanoparticles were predicted to have capability degrading dye compound such as methylene blue in membrane surface. Zhang et al. [35] reported that the interaction of methylene blue and zinc oxide nanoparticles mainly considered as the ionic bonding between the positively charged of $\mathrm{ZnO}\left(\mathrm{Zn}(\mathrm{OH})^{+}\right)$and negatively charged of methylene blue $\left(-\mathrm{SO}_{3}^{-}\right)$.

\section{Flux recovery ratio (FRR)}

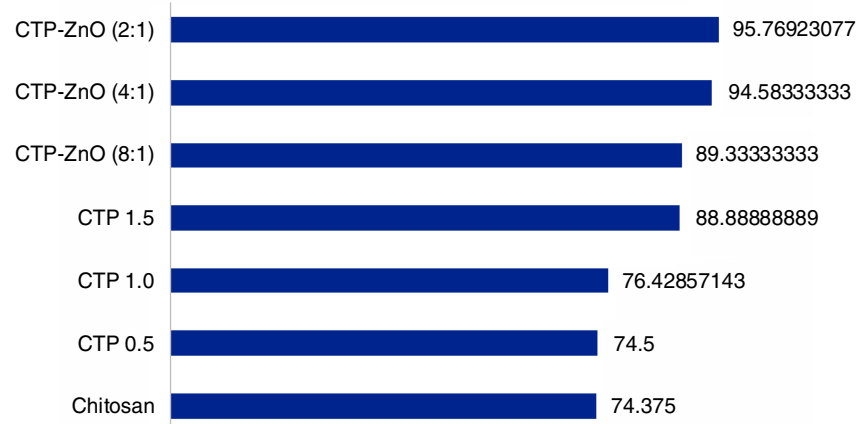

Fig. 10. Flux recovery ratio values of the membranes

\begin{tabular}{|c|c|}
\hline \multicolumn{2}{|c|}{$\begin{array}{c}\text { TABLE-2 } \\
\text { FLUX RECOVERY RATIO (FRR) VALUES }\end{array}$} \\
\hline Sample & FRR $\left(L \cdot m^{-2} h^{-1}\right)$ \\
\hline Chitosan & $74.375 \pm 0.04$ \\
\hline СТP 0,5 & $74.500 \pm 0.02$ \\
\hline CTP 1.0 & $76.426 \pm 0.03$ \\
\hline СТP 1,5 & $88.889 \pm 0.02$ \\
\hline CTP-ZnO (8:1) & $89.333 \pm 0.03$ \\
\hline CTP-ZnO (4:1) & $94.583 \pm 0.02$ \\
\hline CTP-ZnO (2:1) & $95.769 \pm 0.04$ \\
\hline
\end{tabular}




\section{Conclusion}

From the results, some points have been considered as conclusions; (1) the cross-linking between the membrane with TPP can influence the membrane surface, the pore radius increase by the addition of TPP and it had been analyzed by BET; (2) zinc oxide nanoparticles impregnation can affect membrane morphology, making the surface rougher; (3) the nanoparticles also affect the hydrophilicity of the membrane surface, the more zinc oxide nanoparticles were added, the less hydrophilic properties that membranes have; (4) the performance test using methylene blue showed that the addition of zinc oxide nanoparticles in CTP membrane is proven to improve antifouling performance in the membrane as shown by increased flux recovery ratio value.

\section{ACKNOWLEDGEMENTS}

The authors thank Directorate of Research and Community Service of Research and Technology Ministries (DRPM Ristekdikti) for providing the research grant. The authors also thank Dr. Khoiruddin, MT for sharing his experience in making the membrane permeation test instrument.

\section{CONFLICT OF INTEREST}

The authors declare that there is no conflict of interests regarding the publication of this article.

\section{REFERENCES}

1. X. Lu, S. Romero-Vargas Castrillón, D.L. Shaffer, J. Ma and M. Elimelech, Environ. Sci. Technol., 47, 12219 (2013); https://doi.org/10.1021/es403179m.

2. W.I. Mortada, K.A. Nabieh, A.F. Donia, A.M. Ismail and I.M.M. Kenawy, J. Trace Elem. Med. Biol., 36, 52 (2016); https://doi.org/10.1016/j.jtemb.2016.04.004.

3. I.M. Atadashi, M.K. Aroua, A.R.A. Aziz and N.M.N. Sulaiman, Appl. Energy, 88, 4239 (2011);

https://doi.org/10.1016/j.apenergy.2011.05.029.

4. V.K. Thakur and S.I. Voicu, Carbohydr. Polym., 146, 148 (2016); https://doi.org/10.1016/j.carbpol.2016.03.030.

5. C. Bhattacharjee, V.K. Saxena and S. Dutta, Innov. Food Sci. Emerg. Technol., 43, 136 (2017); https://doi.org/10.1016/j.ifset.2017.08.002.

6. J. Zhou, G. Romero, E. Rojas, L. Ma, S. Moya and C. Gao, J. Colloid Interface Sci., 345, 241 (2010); https://doi.org/10.1016/j.jcis.2010.02.004.

7. W. Zhang, L. Ding, J. Luo, M.Y. Jaffrin and B. Tang, Chem. Eng. J., 302, 446 (2016); https://doi.org/10.1016/j.cej.2016.05.071.

8. S. Judd, Trends Biotechnol., 26, 109 (2008); https://doi.org/10.1016/j.tibtech.2007.11.005.

9. R.F.M. Elshaarawy, F.H.A. Mustafa, L. van Geelen, A.E.A. Abou-Taleb, H.R.Z. Tadros, R. Kalscheuer and C. Janiak, Carbohydr. Polym., 172, 352 (2017); https://doi.org/10.1016/j.carbpol.2017.05.059.

10. F.M. Sukma and P.Z. Çulfaz-Emecen, J. Memb. Sci., 545, 329 (2017); https://doi.org/10.1016/j.memsci.2017.09.080.

11. A. Febriasari, D. Siswanta, A.A. Kiswandono and N.H. Aprilita, J. Rekayasa Kim. Lingkung., 11, 99 (2016); https://doi.org/10.23955/rk1.v11i2.5112.

12. A.A. Alshahrani, H. Al-Zoubi, L.D. Nghiem and M. in het Panhuis, Desalination, 418, 60 ( 2017);

https://doi.org/10.1016/j.desal.2017.05.031.
13. S. Tamburaci and F. Tihminlioglu, Mater. Sci. Eng. C, 80, 222 (2017); https://doi.org/10.1016/j.msec.2017.05.069.

14. M. Ahmad, K. Manzoor and S. Ikram, Int. J. Biol. Macromol., 105, 190 (2017); https://doi.org/10.1016/j.ijbiomac.2017.07.008

15. A. Zahir, Z.Aslam, M.S.Kamal, W.Ahmad,A.Abbas and R. A. Shawabkeh, J. Mol. Liq., 244, 211 (2017); https://doi.org/10.1016/j.molliq.2017.09.006.

16. C.C. dos Santos, R. Mouta, M.C.C. Junior and S.A.A. Santana, Carbohydr. Polym., 180, 182 (2018); https://doi.org/10.1016/j.carbpol.2017.09.076.

17. H. Altaher, J. Hazard. Mater, 233-234, 97 (2012); https://doi.org/10.1016/j.jhazmat.2012.06.061.

18. C. Liu, R. Bai and L. Nan, Sodium Tripolyphosphate (TPP) Crosslinked Chitosan Membranes and Application in Humic Acid Removal, AIChE Annual Meeting, Conf. Proceeding, pp. 5561-5574 (2004).

19. M. Mohajeri, H. Akbarpour and V. Karimkhani, Mater. Today Proc., 4, 4906 (2017); https://doi.org/10.1016/j.matpr.2017.04.094.

20. L. Djerahov, P. Vasileva, I. Karadjova, R.M. Kurakalva and K.K. Aradhi, Carbohydr. Polym., 147, 45 (2016); https://doi.org/10.1016/j.carbpol.2016.03.080.

21. R. Cai, H. Wang, M. Cao, L. Hao, L. Zhai, S. Jiang and X. Li, Mater. Des., 87, 17 (2015); https://doi.org/10.1016/j.matdes.2015.08.004.

22. R. Ma, Y.L. Ji, Y.S. Guo, Y.F. Mi, Q.F. An and C.J. Gao, Desalination, 416, 35 (2017); https://doi.org/10.1016/j.desal.2017.04.016.

23. I. Munnawar, S.S. Iqbal, M.N. Anwar, M. Batool, S. Tariq, N. Faitma, A.L. Khan, A.U. Khan, U. Nazar, T. Jamil and N.M. Ahmad, Carbohydr. Polym., 175, 661 (2017); https://doi.org/10.1016/i.carbpol.2017.08.036.

24. N. Ghaemi, J. Colloid Interface Sci., 485, 81 (2017); https://doi.org/10.1016/j.jcis.2016.09.035.

25. S. Mokhtari, A. Rahimpour, A.A. Shamsabadi, S. Habibzadeh and M. Soroush, Appl. Surf. Sci., 393, 93 (2017); https://doi.org/10.1016/j.apsusc.2016.10.005.

26. J. He, A. Cui, S. Deng and J.P. Chen, J. Colloid Interface Sci., 512, 190 (2018); https://doi.org/10.1016/j.jcis.2017.09.106.

27. Minkal. M. Ahuja and D.C. Bhatt, Int. J. Biol. Macromol., 106, 1184 (2017); https://doi.org/10.1016/j.ijbiomac.2017.08.128.

28. A. Gnanaprakasam, V.M. Sivakumar, P.L. Sivayogavalli and M. Thirumarimurugan, Ecotoxicol. Environ. Saf., 121, 121 (2015); https://doi.org/10.1016/j.ecoenv.2015.04.043.

29. Z. Xu, X. Li, K. Teng, B. Zhou, M. Ma, M. Shan, K. Jiao, X. Qian and J. Fan, J. Membr. Sci., 535, 94 (2017); https://doi.org/10.1016/j.memsci.2017.04.029.

30. J. Kalmár, G. Lente and I. Fábián, Dyes Pigments, 127, 170 (2016); https://doi.org/10.1016/j.dyepig.2015.12.025.

31. C.P. Kiilll, H.S. Barud, S.H. Santagneli, S.J.L. Ribeiro, A.M. Silva, A. Tercjak, J. Gutierrez, A.M. Pironi and M.P.D. Gremião, Carbohydr. Polym., 157, 1695 (2017); https://doi.org/10.1016/j.carbpol.2016.11.053.

32. F. Rázga, D. Vnuková, V. Némethová, P. Mazancová and I. Lacík, Carbohydr. Polym., 151, 488 (2016); https://doi.org/10.1016/j.carbpol.2016.05.092.

33. S.H. Woo, B.R. Min and J.S. Lee, Separ. Purif. Tech., 187, 274 (2017); https://doi.org/10.1016/j.seppur.2017.06.030.

34. Y. Feng, K. Wang, C. Davies and H. Wang, Nanomaterials, 5, 1366 (2015); https://doi.org/10.3390/nano5031366.

35. F. Zhang, J. Lan, Y. Yang, T. Wei, R. Tan and W. Song, J. Nanopart. Res., 15, 2034 (2013); https://doi.org/10.1007/s11051-013-2034-2. 